\title{
EGU21-9185
}

https://doi.org/10.5194/egusphere-egu21-9185

EGU General Assembly 2021

(c) Author(s) 2021. This work is distributed under

the Creative Commons Attribution 4.0 License.

\section{Near-Surface High Resolution Characterization of the Seismogenic Alhama de Murcia Strike-slip Fault}

\author{
Handoyo Handoyo ${ }^{1}$, Imma Palomeras ${ }^{2}$, Juan Alcalde ${ }^{1}$, Irene de Felipe ${ }^{1}$, David Martí ${ }^{3}$, Julian García- \\ Mayordomo ${ }^{4}$, Jose Jesus Martínez-Díaz ${ }^{5}$, Teresa Teixidor ${ }^{6}$, Juan Miguel Insúa-Arevalo ${ }^{5}$, and Ramon \\ Carbonell $^{1}$ \\ ${ }^{1}$ Geosciences Barcelona, (Geo3BCN-CSIC) Spain (handoyo.geophysics@gmail.com) \\ ${ }^{2}$ University of Salamanca, Salamanca, Spain \\ ${ }^{3}$ Lithica SCCL, Santa Coloma de Farners, Girona, Spain \\ ${ }^{4}$ Geological and Mining Institute of Spain, Madrid, Spain \\ ${ }^{5}$ Universidad Complutense de Madrid, Madrid, Spain \\ ${ }^{6}$ Universidad de Granada, Granada, Spain
}

In Spring 2011 ( $11^{\text {th }}$ of May), the vicinity of Lorca city (Murcia, SE Iberian Peninsula) was hit by two main seismic shocks that reach a maximum magnitude of $5.2 \mathrm{Mw}$. The earthquake caused serious widespread damage in the city and its surroundings. Similar events have affected the area regularly in the past (for example: on May 6,1977, $4.2 \mathrm{mg}$ ). These events are distributed along a relatively broad band (roughly NE-SW oriented) parallel to the coast, associated to the activation of the Alhama de Murcia Fault (AMF), an oblique-slip (reverse-strike-slip) fault system located in the Eastern Betics Shear Zone. The current study aims to characterize the shallow subsurface across some of the surface outcrop of a few of the main faults that lie within this seismogenic strike-slip fault system. Six normal-incidence seismic reflection profiles were acquired in the area crossing the AMF and the Carrascoy fault, among others). This study focuses on the determination of the shear-wave velocity depth model by applying Multichannel Analysis of Surface Waves (MASW), using the shot records of the seismic reflection profiles. The 1D velocity-depth functions acquired were pasted together to obtain the final 2D velocity models. The hand-picked dispersion curves were inverted using two different approaches to address the consistency of the inversion schemes. The final models reveal relevant differences across the different fault zones, reflecting the heterogeneity and lateral variability that characterizes a complex seismogenic zone, a most probably, diffuse plate boundary.

This research is supported by: Generalitat de Catalunya (AGAUR) grant 2017SGR1022 (GREG); EU (H2020) 871121 (EPOS-SP); EIT-RawMaterials 17024 (SIT4ME), CGL2013-47412-C2-1-P. 